\title{
Hot and Cold Spot Areas of Household Tuberculosis Transmission in Southern China: Effects of Socio-Economic Status and Mycobacterium tuberculosis Genotypes
}

\author{
Zhezhe Cui ${ }^{1,2,+} \oplus$, Dingwen Lin ${ }^{1,+}$, Virasakdi Chongsuvivatwong ${ }^{2, *} \oplus$, Edward A. Graviss ${ }^{3}(\mathbb{D}$, \\ Angkana Chaiprasert ${ }^{4}$, Prasit Palittapongarnpim ${ }^{5}$, Mei Lin ${ }^{1}$, Jing $\mathrm{Ou}^{1}$ and Jinming Zhao ${ }^{1}$ \\ 1 Department of Tuberculosis Control, Guangxi Zhuang Autonomous Region Center for Disease \\ Control and Prevention, Nanning 530028, China; czz6997@163.com (Z.C.); drldw@163.com (D.L.); \\ gxlinmei@126.com (M.L.); gxjfk@163.com (J.O.); yd0414zhjm@163.com (J.Z.) \\ 2 Epidemiology Unit, Faculty of Medicine, Prince of Songkla University, Songkhla 90110, Thailand \\ 3 Department of Pathology and Genomic Medicine, The Center for Molecular and Translational Human \\ Infectious Diseases Research, Houston Methodist Research Institute, Houston, TX 77030, USA; \\ eagraviss@houstonmethodist.org \\ 4 Office for Research and Development, Faculty of Medicine Siriraj Hospital, Mahidol University, \\ Bangkok 10700, Thailand; angkana.cha@mahidol.ac.th \\ 5 Department of Microbiology, Faculty of Science, Mahidol University, Bangkok 10700, Thailand; \\ prasit.pal@mahidol.ac.th \\ * Correspondence: cvirasak@medicine.psu.ac.th \\ + These authors contributed equally to this work.
}

Received: 19 April 2019; Accepted: 23 May 2019; Published: 27 May 2019

\begin{abstract}
The aims of the study were: (1) compare sociodemographic characteristics among active tuberculosis (TB) cases and their household contacts in cold and hot spot transmission areas, and (2) quantify the influence of locality, genotype and potential determinants on the rates of latent tuberculosis infection (LTBI) among household contacts of index TB cases. Parallel case-contact studies were conducted in two geographic areas classified as "cold" and "hot" spots based on TB notification and spatial clustering between January and June 2018 in Guangxi, China, using data from field contact investigations, whole genome sequencing, tuberculin skin tests (TSTs), and chest radiographs. Beijing family strains accounted for $64.6 \%$ of Mycobacterium tuberculosis (Mtb) strains transmitted in hot spots, and $50.7 \%$ in cold spots $(p$-value $=0.02)$. The positive TST rate in hot spot areas was significantly higher than that observed in cold spot areas ( $p$-value $<0.01)$. Living in hot spots (adjusted odds ratio $(\mathrm{aOR})=1.75,95 \%$, confidence interval $(\mathrm{CI}): 1.22,2.50)$, Beijing family genotype $(\mathrm{aOR}=1.83,95 \% \mathrm{CI}: 1.19,2.81)$, living in the same room with an index case $(\mathrm{aOR}=2.29,95 \% \mathrm{CI}: 1.5$, 3.49), travelling time from home to a medical facility ( $\mathrm{aOR}=4.78,95 \% \mathrm{CI}: 2.96,7.72)$, history of Bacillus Calmette-Guérin vaccination ( $\mathrm{aOR}=2.02,95 \% \mathrm{CI}$ : 1.133 .62$)$, and delay in diagnosis $(\mathrm{aOR}=2.56$, $95 \%$ CI: $1.13,5.80$ ) were significantly associated with positive TST results among household contacts of TB cases. The findings of this study confirmed the strong transmissibility of the Beijing genotype family strains and this genotype's important role in household transmission. We found that an extended traveling time from home to the medical facility was an important socioeconomic factor for $\mathrm{Mtb}$ transmission in the family. It is still necessary to improve the medical facility infrastructure and management, especially in areas with a high TB prevalence.
\end{abstract}

Keywords: tuberculosis; genotypes; socioeconomic; transmission; household; contact 


\section{Introduction}

Tuberculosis (TB) continues to be a global concern because of its high infectivity, pathogenicity, mortality, and cost of therapy. In addition to the extra social and clinical burdens associated with TB disease, the patients' family (and caregivers) are also at an increased risk of being infected with the Mycobacterium tuberculosis (Mtb) bacteria [1]. In 2017, the estimated number of TB cases in China was the second highest globally [2]. The realization of the End TB Strategy proposed by the World Health Organization (WHO) is directly related to the performance of TB control in China.

Guangxi Province is an autonomous region located in southern China. In addition to being one of the poorest provinces with the majority of the population being farmers, Guangxi is also regarded as a high TB notification region with 45,000 new TB cases reported annually by the National Notifiable Disease Reported System (NNDRS). Most TB patients come from rural areas where health resources are scarce [3]. From a previous spatiotemporal study, the TB notification rate in Guangxi was reported to be distributed unevenly at the county level [4]. Through the spatial autocorrelation analysis of our baseline survey in this study, we detected significantly high TB notification clusters (Moran's I index between adjacent areas were close to 1) and significantly low zones (Moran's I index between adjacent areas were close to -1) [5]. We defined the former as "hot spots" and the latter as "cold spots". Based on this spatial feature, six counties in hot and cold spots were selected as the study sites as shown in Figure 1. In addition, the hot spot areas are inhabited by minorities, especially the Zhuang ethnic group, while the cold spot areas are inhabited mainly by the Han population (China's main ethnic group). Some parts of China have reported a higher prevalence of TB in ethnic minority areas compared to areas where a majoring of the population are Han [6]. With this background, we have considered ethnicities as a potential risk factor in this study. Although there are large ethnic differences, by field investigation, we found that the living environment of residents in the two regions were similar and not considered overcrowded (about $30 \mathrm{~m}^{2}$ per family member).

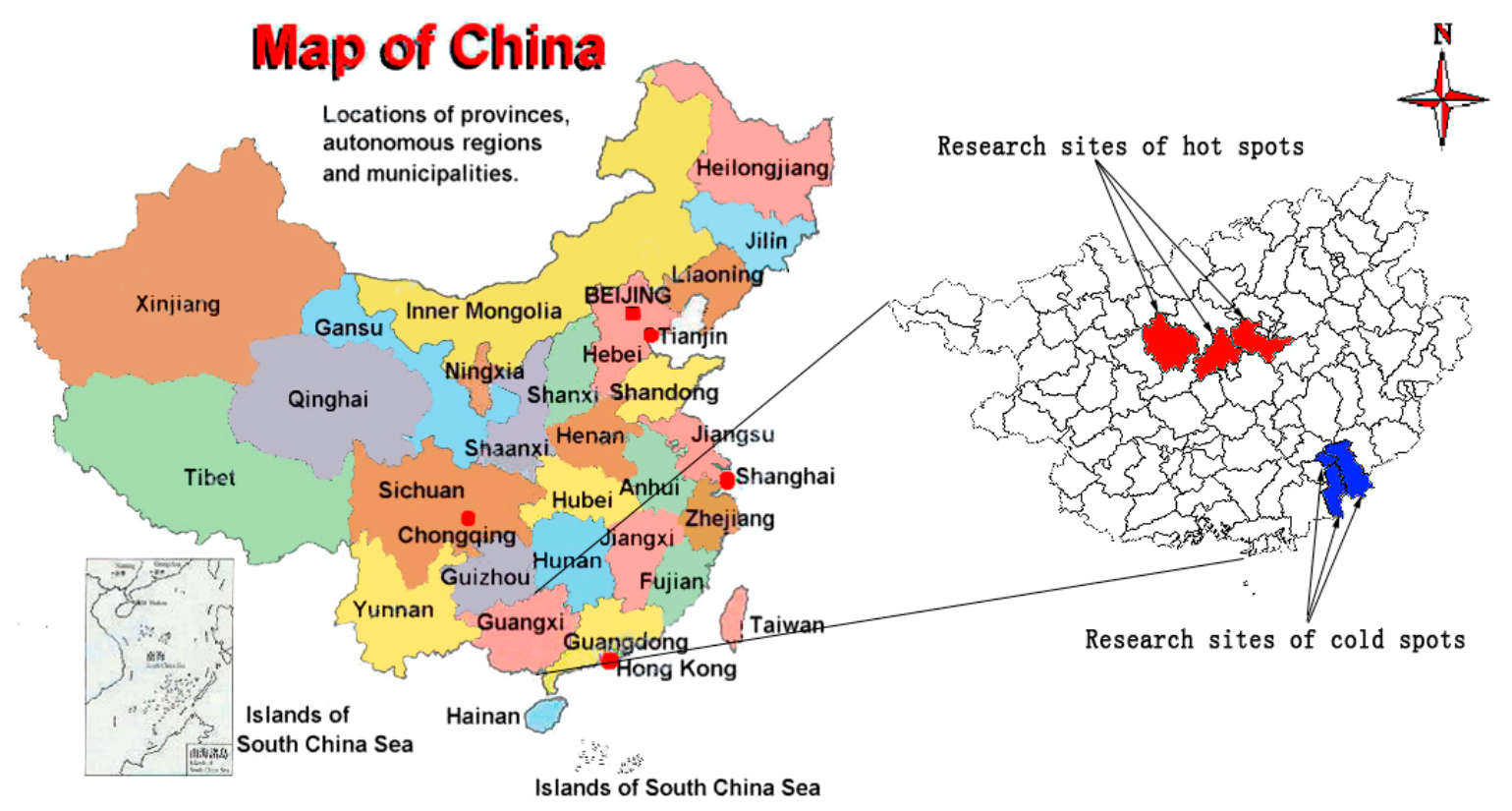

Figure 1. Research sites of hot and cold spots in Guangxi, China.

Mtb strain-specific genomic diversity is an important factor in TB pathogenesis. Genomic diversity affects virulence, transmissibility, host response, and the emergence of drug-resistance. Of the seven major lineages of Mtb worldwide, the Beijing family strains belonged to Lineage 2 (the East-Asian lineage) and are widely prevalent in Eastern Asia, especially China [7,8]. Mycobacterial virulence plays an important role in the dissemination process of the TB disease [9]. Mtb Lineage 2, Lineage 3, and Lineage 4 strains are known to have virulent phenotypes compared to Mtb Lineage 1, Lineage 5 , 
Lineage 6, and Lineage 7 [10]. Case-control studies and cohort studies have been conducted to analyze the characteristics of the Beijing family (Mtb Lineage 2.2) because of its association with drug resistance, high relapse rates, and pathogenicity [11-13]. However, there are few published studies about the Beijing family strain's transmissibility in households. In addition, whole genome sequencing-based single-nucleotide polymorphisms (SNPs) as robust (stable) markers of genetic variation has been widely applied for phylogenetic analysis [14]. Due to the high resolution and stable inheritance, whole genome sequencing (WGS) is more discriminating than traditional Mtb genotyping methods such as mycobacterial interspersed repetitive unit-variable-number tandem repeat (MIRU-VNTR) typing and spatial oligonucleotide typing (spoligotyping) [10].

$\mathrm{Mtb}$ is transmitted from person to person via droplets. Therefore, people who are in close contact with TB patients are more likely to be infected with $\mathrm{Mtb}$. A case-control study conducted in Ethiopia has shown that individuals that had a TB household member had an increased risk of developing TB by 3-fold [15]. Systematic TB contact tracing at the household level is not only an effective method to detect secondary cases of TB but the method is also an important epidemiologic tool to understand the transmission dynamics and prognostic factors of TB transmission in households [16,17]. Commonly used TB surveillance methods include a questionnaire survey, tuberculin skin test (TST) and chest imaging examination of household contacts of tuberculosis patients $[17,18]$. However, most studies ignore the influence of the bacteria with different genotypes and their interactions with the host's environment on transmission.

With the increasing availability of WGS technology in China, it has become appropriate to determine which (and if) Mtb genotypes play a role in the intra-household transmission of TB disease in both hot and cold spots (areas with no clear pattern of spatial clustering). Thus, this study aimed to compare sociodemographic characteristics and $\mathrm{Mtb}$ genotype patterns among active TB cases in cold and hot transmission spots and quantify the influences of genotype, locality and potential determinants on the rates of LTBI among household contacts of index cases.

\section{Methods}

\subsection{Ethics Approval}

This study was approved by the Institutional Review Board of the Guangxi Center for Disease Control and Prevention (CDC) (GW-2017-0001) and the Research Ethics Committee of Prince of Songkla University (60-286-18-6). Both committees approved the informed consent procedure. All participants provided written informed consent to participate in this study.

\subsection{Study Design}

Two parallel case-contact studies in the cold and hot spot TB transmission areas of Guangxi Province were conducted from January to June 2018. We consecutively enrolled eligible pulmonary TB patients at county hospitals in these two areas and followed their household contacts. By comparing the different subgroups, in these study-targeted areas, we investigated the differences in the prevalence and transmissibility of Mtb at the household level.

\subsection{Study Setting}

Six Guangxi Province counties, including three "hot spots" and three "cold spots" of TB transmission, were identified based on TB notification spatial clustering analysis. Patients who were suspected as having pulmonary TB were confirmed at the county hospital with sputum smear, chest radiography and sputum culture. Only culture-positive TB cases were prospectively recruited. Cultured Mtb isolates were transported to the Guangxi CDC where Mtb DNA extraction occurred before shipping of mycobacterial DNA to Zeta Biosciences (Shanghai) for WGS. Clinical investigations of the TB patients and their contacts were conducted by a local hospital team under the supervision of Guangxi CDC. Clinical and laboratory data of the TB patients were routinely entered into the NNDRS 
which is overseen by Guangxi CDC. The local hospital team collected additional data from household contacts of TB cases by face-to-face interviews with household members after consent.

\subsection{Study Participants and Selection Methods}

\subsubsection{Sample Size}

The sample size for household contacts was calculated based on the two independent proportions formula [19]. According to a previous study of major genotypes (Beijing strains) in Guangxi, the estimated proportion of the Beijing family genotype was $70 \%$ in hot spot areas and $50 \%$ in cold spot areas [20]. With a type I error of 0.05 and a power of $90 \%$, at least 124 active TB cases in each area were required. We estimated that 310 household contacts in each area would be recruited based on the screening rate from a pilot study.

\subsubsection{Eligibility Criteria for Index Cases}

All individuals confirmed as having pulmonary TB at the county hospital of hot and cold spot areas were recruited, and eligible index TB cases must have been a resident in one of six counties for at least two years prior to TB case identification. Individuals with TB who were unable to communicate with research staff were excluded.

\subsubsection{Whole Genome Sequencing and Genotyping Performance}

At the Guangxi CDC, a genetic sample kit (HiPure Bacterial DNA Kit, Magen Biotech Co. Ltd., Xuzhou, China) was used for Mtb DNA extraction. At Zeta Biosciences (Shanghai, China), next generation sequencing library preparations were constructed following the manufacturer's protocol (Illumina TruSeq DNA Nano Library Prep Kit, Illumina, Inc., San Diego, CA, USA). For each sample, 100 ng DNA was randomly fragmented to $<500$ bp by sonication (Covaris S220, Covaris, Inc., Woburn, MA, USA). The fragments were treated with End Prep Enzyme Mix for end repairing and with A-Tailing Mix for dA-tailing, followed by a T-A ligation to add adaptors to both ends. Size selection of Adaptor-ligated DNA was then performed using SPB Beads, and fragments of $\sim 410 \mathrm{bp}$ (with the approximate insert size of $350 \mathrm{bp}$ ) were recovered. Each sample was then amplified by PCR for eight cycles using P5 and P7 primers, with both primers carrying sequences which can anneal with flowcell to perform a bridge PCR and P7 primer carrying a six-base index allowing for multiplexing. The PCR products were cleaned up using SPB Beads, validated using an Agilent 2100 Bioanalyzer (Agilent Technologies, Palo Alto, CA, USA) and quantified by Qubit2.0 Fluorometer (Invitrogen, Carlsbad, CA, USA). Libraries with different indices were subsequently multiplexed and loaded on an Illumina HiSeq instrument according to the manufacturer's instructions (Illumina, San Diego, CA, USA). Sequencing was carried out using a $2 \times 150$ paired-end (PE) configuration; image analysis and base calling were conducted by the HiSeq Control Software (HCS) + OLB + GAPipeline-1.6 (Illumina) on the HiSeq instrument. Mycobacterium tuberculosis WGS data files in the FASTQ format of each sample were trimmed with Trimmomatic v0.3.2. Trimmomatic cut bases off at the start of a read if the quality score was under 3 and retained reads at a minimal length of $91 \mathrm{bp}$. Trimmed paired-end reads ware aligned using Bowtie2 v2.3.0 against the genome of Mycobacterium tuberculosis H37Rv (Genbank accession: AL123456.3) with the parameter "-very-sensitive". SNPs were identified using VarScan v2.3.8 and SAMtools v1.3.1; variations with a coverage under 30X or the minimal frequency of the homozygote below 0.99 were ignored. Further filter-ware was applied to all the VCF files using bcftools v1.9. In the filter criteria, heterozygous SNP or SNP within 5 bp of an indel was filtered. SNPs with a genotype quality below 255 or mapped alleles depth under 100x were also discarded. Variations in the coding sequence of proteins that contain proline-glutamate or proline-proline-glutamate motifs were characterized by Genebank's annotation and filtered from downstream analysis. Finally, 26,869 SNPs remained after filtering. VCF-kit was use to concentrate all the remaining SNPs into pseudo-sequences for phylogeny analysis. A maximum-likelihood phylogeny 
was reconstructed using RAxML v8.1.9 with a general time-reversible (GTR) nucleotide substitution model and 100 bootstrap replicates; the GAMMA model of rate heteorgeneity was estimated by RAxML itself [21]. Finally, the crude and filtered fasta-files, vcf files, spleen necrosis virus matrix, classified spoligotype and lineage genotype data, and the gene structure difference coefficient (Fst) between hot and cold spot areas of TB were delivered to the Guangxi CDC for downstream data analysis.

\subsubsection{Household Contacts}

Following consent of the index TB cases and their family members, contact tracing was conducted on immediate household contacts of index TB cases if they lived with the index TB case for more than three months. Children under the age of five were excluded. For interviewees with limited understanding, their immediate family members were used as a proxy. In order to screen for active TB among household contacts, a Mantoux TST and chest radiography were used in parallel.

\subsubsection{Tuberculin Skin Tests for Mtb Infection}

As recommended by China's National Tuberculosis Control Program, the TST was carried out by the Mantoux method injecting a 5 tuberculin unit dose of BCG purified protein derivative (Beijing Sanroad Biological Products Co. Ltd., Beijing, China) into the volar surface of the forearm. The TST injection was performed by trained nurses from the local TB clinic and was made with a 1-mL tuberculin syringe with the needle bevel facing upward. Identification marks for the furthest induration points from the inoculation site were made on the skin. The TST reaction was read between 48 and $72 \mathrm{~h}$ by TB clinic doctors. A patient who did not return within $72 \mathrm{~h}$ was given a reappointment for another TST. A patient with an average diameter of induration $\geq 10 \mathrm{~mm}$ was considered as an Mtb-infected individual [22-24].

\subsubsection{Secondary and LTBI Identification}

TST and chest radiography positive subjects with suspected TB symptoms were identified and recorded and their sputa were sent for laboratory examination. To confirm TB diagnosis, the study team used a sputum alpha-fetoprotein smear and culture with drug sensitivity testing and a genotype test. Characteristic features of the index cases were analyzed in relation to active TB positivity results. Household contacts who had TSTs with an induration $\geq 10 \mathrm{~mm}$ and who were diagnostically excluded from the possibility of active TB were identified as having latent TB infection.

\subsection{Variables and Data Collection}

Household-level variables obtained from TB cases and their household contacts included: the average age and body mass index (BMI) of all contacts, number of family members, size of living area, the average diameter of induration, and the TST positive rate. Individual variables included: occupation, ethnicity, education status, marital status, duration of living at the present address, income, history of household contact with the TB patient, history of smoking, history of drinking, history of BCG vaccination, travel history, travelling time from home to medical facility, TB symptoms, severity of TB symptoms, delay in TB diagnosis, BMI, other chronic or immunocompromising diseases, HIV status, and diabetes mellitus status (self-report). Structured and piloted questionnaires were used to collect all information about individuals and household-level data.

\subsection{Data Management and Analysis}

Epi Data (version 3.1) was used for double entering of the data at regular intervals while R (v 3.3.2) was used for data management and analysis. MEGA-X (v 10.0.5) and Fig Tree (v 1.4.4) were used for editing phylogenetic trees.

Univariate analysis was initially used to assess the differences of variables between hot and cold spot areas and Mtb-infected individuals versus No-Mtb infected individuals. Variables with $p$-values 
$<0.20$ [25] and those deemed as important covariates were included in a multivariate mixed-effects model in which the household identifier was the clustering unit. Statistical significance was determined by using a $p$-value $<0.05$.

\section{Results}

A total of 315 potentially eligible index TB cases with complete diagnostic data were identified. Twenty-four TB cases were excluded due to refusal to participate, non-tuberculosis mycobacteria (NTM) or low quality of Mtb DNA (Figure 2). Of the remaining 291 enrolled TB index patients and their 761 household contacts, we excluded 144 because of refusal to participate, difficulties in communication and lack of diagnostic data. Consequently, we included 291 index cases (147 from hot spot areas and 144 from cold spot areas) and their 617 household contacts ( 311 from hot spot areas and 306 from cold spot areas). Two secondary TB cases and 185 TST positive household contacts were detected in this study. The maximum induration size in TST positive cases was $23 \mathrm{~mm}$.

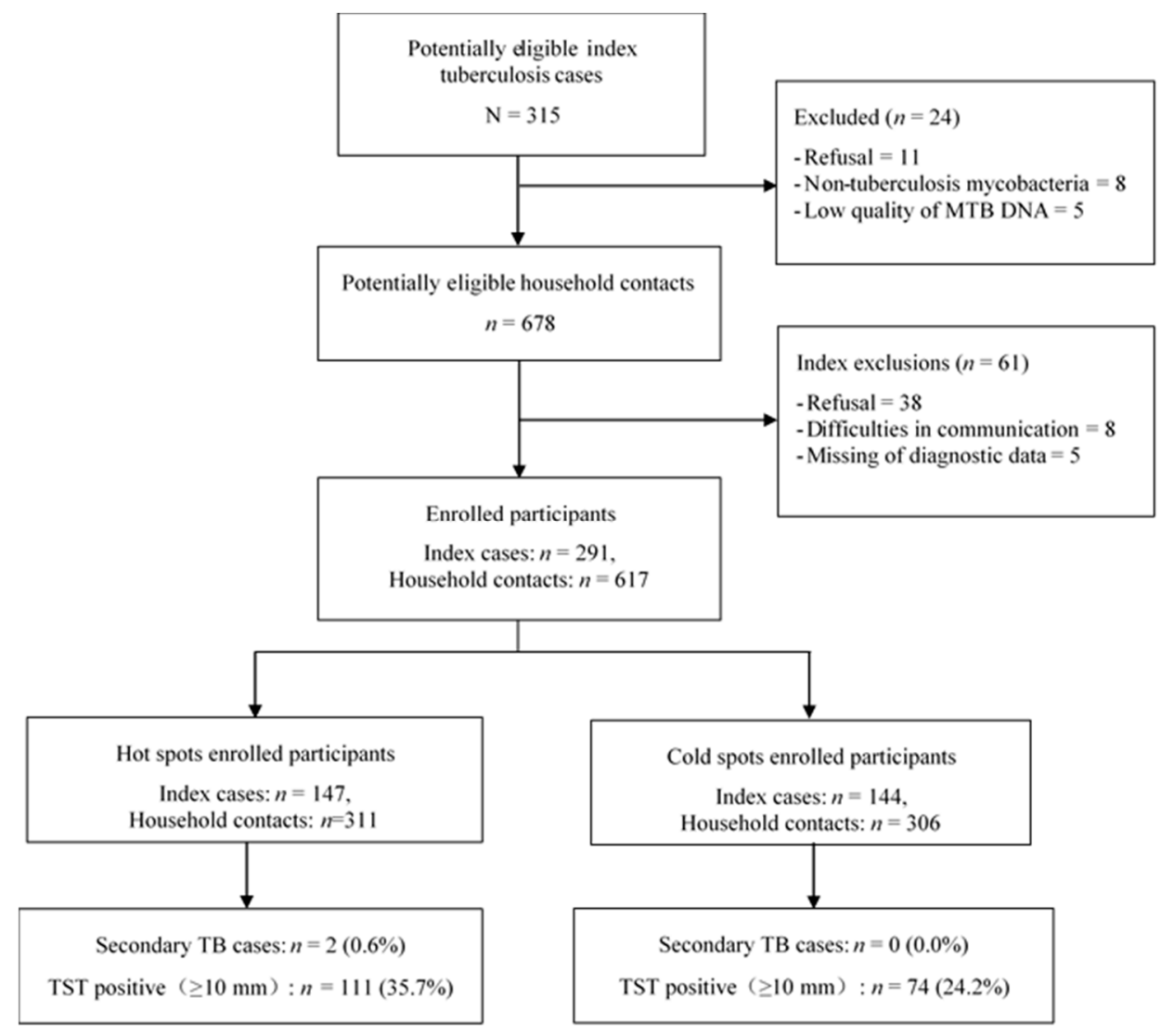

Figure 2. Profile of household Mtb transmission study.

\subsection{Characteristics of Index Cases and Household Contacts}

Table 1 shows a comparison of various county and individual level factors between the two geographical areas. We identified three hot spot counties having a population of 1.5 million and three cold spot counties with a population of 2.7 million. Counties in hot spot areas had a higher prevalence of multi-drug resistant TB and a higher mortality rate than those in cold spot areas, but had a lower per capita gross domestic product, percentage of Han ethnicity, and number of hospitals. At the individual level, hot spot areas had a higher proportion of elderly, Zhuang minority, less educated, low-income earners, and underweight TB cases who had a delay in their diagnosis and sputum smear with more than $2+$ strong smear-positive cases. 
Table 1. Comparison of characteristics of TB index cases between cold and hot spot areas.

\begin{tabular}{|c|c|c|c|}
\hline Variable & Cold Spots $(n, \%)$ & Hot Spots $(n, \%)$ & $p$-Value \\
\hline \multicolumn{4}{|l|}{ County-level } \\
\hline Number of counties & 3 & 3 & \\
\hline GDP per capita (Renminbi) & 35,268 & 17,556 & \\
\hline Proportion of Han ethnicity (\%) & 97.67 & 31.67 & \\
\hline Prevalence of MDR-TB (\%) & 0.20 & 1.69 & \\
\hline Mortality rate & 0.08 & 0.14 & \\
\hline Number of hospitals & 29 & 10 & \\
\hline \multicolumn{4}{|l|}{ Individual-level } \\
\hline Total number & $144(100.0)$ & $147(100.0)$ & \\
\hline Gender & & & 0.740 \\
\hline Male & $114(79.2)$ & $113(76.9)$ & \\
\hline Female & $30(20.8)$ & $34(23.1)$ & \\
\hline Age group (years) & & & 0.009 \\
\hline$<20$ & $7(4.9)$ & $5(3.4)$ & \\
\hline $20-29$ & $21(14.6)$ & $5(3.4)$ & \\
\hline $30-39$ & $26(18.1)$ & $19(12.9)$ & \\
\hline $40-49$ & $21(14.6)$ & $27(18.4)$ & \\
\hline $50-59$ & $24(16.7)$ & $35(23.8)$ & \\
\hline$\geq 60$ & $45(31.2)$ & $56(38.1)$ & \\
\hline Ethnicity & & & $<0.001$ \\
\hline Han & $139(96.5)$ & $5(3.4)$ & \\
\hline Zhuang & $4(2.8)$ & $130(88.4)$ & \\
\hline Others & $1(0.7)$ & $12(8.2)$ & \\
\hline Education & & & $<0.001$ \\
\hline None & $2(1.4)$ & $18(12.2)$ & \\
\hline Primary school & $45(31.2)$ & $66(44.9)$ & \\
\hline Middle school & $52(36.1)$ & $44(29.9)$ & \\
\hline High school & $38(26.4)$ & $19(12.9)$ & \\
\hline University & $7(4.9)$ & $0(0)$ & \\
\hline Occupation & & & 0.056 \\
\hline Farmer & $101(70.1)$ & $116(78.9)$ & \\
\hline Migrant worker & $14(9.7)$ & $14(9.5)$ & \\
\hline Student & $10(6.9)$ & $1(0.7)$ & \\
\hline Civil servant & $1(0.7)$ & $2(1.4)$ & \\
\hline Others & $18(12.5)$ & $14(9.5)$ & \\
\hline Marital status & & & 0.435 \\
\hline Married & $112(77.8)$ & $123(83.7)$ & \\
\hline Single & $26(18.1)$ & $19(12.9)$ & \\
\hline Others & $6(4.2)$ & $5(3.4)$ & \\
\hline Income per month (Renminbi) & & & $<0.001$ \\
\hline$<3000$ & $100(69.4)$ & $133(90.5)$ & \\
\hline $3000-4000$ & $21(14.6)$ & $12(8.2)$ & \\
\hline $4000-5000$ & $17(11.8)$ & $1(0.7)$ & \\
\hline$>5000$ & $6(4.2)$ & $1(0.7)$ & \\
\hline Number of TB patients in family & & & 0.082 \\
\hline None & $132(91.7)$ & $124(84.4)$ & \\
\hline One or more & $12(8.3)$ & $23(15.6)$ & \\
\hline
\end{tabular}


Table 1. Cont.

\begin{tabular}{|c|c|c|c|}
\hline Variable & Cold Spots $(n, \%)$ & Hot Spots $(n, \%)$ & $p$-Value \\
\hline History of smoking & & & 0.696 \\
\hline Never & $73(50.7)$ & $70(47.6)$ & \\
\hline Former & $48(33.3)$ & $48(32.7)$ & \\
\hline Current & $23(16)$ & $29(19.7)$ & \\
\hline History of drinking alcohol & & & 0.289 \\
\hline Never & $98(68.1)$ & $87(59.2)$ & \\
\hline Former & $28(19.4)$ & $36(24.5)$ & \\
\hline Current & $18(12.5)$ & $24(16.3)$ & \\
\hline HIV status & & & 0.918 \\
\hline Negative & $136(94.4)$ & $139(94.6)$ & \\
\hline Positive & $2(1.4)$ & $1(0.7)$ & \\
\hline Unknown & $6(4.2)$ & $7(4.8)$ & \\
\hline Diabetes status & & & 0.134 \\
\hline Negative & $122(84.7)$ & $111(75.5)$ & \\
\hline Positive & $21(14.6)$ & $33(22.4)$ & \\
\hline Unknown & $1(0.7)$ & $3(2)$ & \\
\hline BCG vaccination history & & & 0.964 \\
\hline Unvaccinated & $32(22.2)$ & $34(23.1)$ & \\
\hline Vaccinated & $112(77.8)$ & $113(76.9)$ & \\
\hline BMI $\left(\mathrm{kg} / \mathrm{m}^{2}\right)$ & & & $<0.001$ \\
\hline$<18$ & $11(7.6)$ & $39(26.5)$ & \\
\hline $18-24.99$ & $127(88.2)$ & $101(68.7)$ & \\
\hline$\geq 25$ & $6(4.2)$ & $7(4.8)$ & \\
\hline Outside travel greater than 3 months & & & 0.017 \\
\hline No & $110(76.4)$ & $129(87.8)$ & \\
\hline Yes & $34(23.6)$ & $18(12.2)$ & \\
\hline Severity of TB symptoms & & & 0.587 \\
\hline Median (IQR) & $2(1,2)$ & $2(1,2)$ & \\
\hline Delay of TB Diagnosis & & & 0.038 \\
\hline Yes & $121(82.6)$ & $136(92.5)$ & \\
\hline No & $23(17.4)$ & $11(7.5)$ & \\
\hline Retreat & & & 0.135 \\
\hline No & $127(88.2)$ & $138(93.9)$ & \\
\hline Yes & $17(11.8)$ & $9(6.1)$ & \\
\hline Smear result & & & $<0.001$ \\
\hline Median (IQR) & $2+(1+, 2+)$ & $3+(2+, 3+)$ & \\
\hline $\begin{array}{l}\text { Travelling time from home to } \\
\text { medical facility }\end{array}$ & & & 0.103 \\
\hline Greater than one hour & $53(36.8)$ & $40(27.2)$ & \\
\hline Within one hour & $91(63.2)$ & $107(72.8)$ & \\
\hline
\end{tabular}

TB: Tuberculosis. GDP: Gross domestic product. IQR: Inter-quartile range. MDR-TB: Multi-drug resistant tuberculosis.

Table 2 summarizes the characteristics of household contacts of index TB cases. Ethnicity, education level, and income of family contacts were consistent with the index case. In addition, migrant work, living with the index cases, having suspected TB symptoms and a positive TST (induration $\geq 10 \mathrm{~mm}$ ), 
and having a higher percentage of TB cases in hot spot areas were significantly high $(p<0.05)$. Table 3 compares the aggregated values of characteristics of the households of the two areas. The average diameter of induration and the positive TST rate in the household were significantly higher in the hot spots $(p<0.05)$.

Table 2. Comparison of characteristics of the household contacts between cold and hot spot transmission areas.

\begin{tabular}{|c|c|c|c|}
\hline Variables & Cold Spots $n=306$ & Hot Spots $n=311$ & $p$-Value \\
\hline Relationship with index cases & & & 0.819 \\
\hline Non-spouse & $220(71.9)$ & $220(70.7)$ & \\
\hline Spouse & $86(28.1)$ & $91(29.3)$ & \\
\hline Live together with index cases & & & $<0.001$ \\
\hline Live separate & $196(64.1)$ & $126(40.5)$ & \\
\hline Live in same room & $110(35.9)$ & $185(59.5)$ & \\
\hline Local residence & & & 0.725 \\
\hline Local & $303(99)$ & $306(98.4)$ & \\
\hline Immigration & $3(1)$ & $5(1.6)$ & \\
\hline Gender & & & 0.605 \\
\hline Male & $152(49.7)$ & 147 (47.3) & \\
\hline Female & $154(50.3)$ & $164(52.7)$ & \\
\hline Age group (years) & & & 0.886 \\
\hline $5-14$ & $39(12.7)$ & $44(14.1)$ & \\
\hline $15-40$ & $103(33.7)$ & $104(33.4)$ & \\
\hline $40-59$ & $106(34.6)$ & $100(32.2)$ & \\
\hline$\geq 60$ & $58(19)$ & $63(20.3)$ & \\
\hline Ethnicity & & & $<0.001$ \\
\hline Han & $298(97.4)$ & $31(10)$ & \\
\hline Zhuang & $8(2.6)$ & $247(79.4)$ & \\
\hline Others & $0(0.0)$ & $33(10.6)$ & \\
\hline Education & & & $<0.001$ \\
\hline None & $9(2.9)$ & $37(11.9)$ & \\
\hline Primary school & $114(37.3)$ & $128(41.2)$ & \\
\hline Middle school & $113(36.9)$ & $100(32.2)$ & \\
\hline High school & $51(16.7)$ & $31(10)$ & \\
\hline University & $19(6.2)$ & $15(4.8)$ & \\
\hline Occupation & & & $<0.001$ \\
\hline Farmer & $211(69.0)$ & $164(52.7)$ & \\
\hline Migrant worker & $16(5.2)$ & $37(11.9)$ & \\
\hline Student & 42 (13.7) & $62(19.9)$ & \\
\hline Civil servant & $5(1.6)$ & $6(1.9)$ & \\
\hline Others & $32(10.5)$ & $42(13.5)$ & \\
\hline Marital status & & & 0.179 \\
\hline Married & $201(65.7)$ & 205 (65.9) & \\
\hline Single & $84(27.5)$ & $73(23.5)$ & \\
\hline Others & $21(6.9)$ & $33(10.6)$ & \\
\hline Income per month (Renminbi) & & & 0.011 \\
\hline$\leq 3000$ & $225(73.5)$ & $262(84.2)$ & \\
\hline $3001-4000$ & $55(18)$ & $33(10.6)$ & \\
\hline $4001-5000$ & $22(7.2)$ & $13(4.2)$ & \\
\hline$>5000$ & $4(1.3)$ & $3(1)$ & \\
\hline
\end{tabular}


Table 2. Cont.

\begin{tabular}{|c|c|c|c|}
\hline Variables & Cold Spots $n=306$ & Hot Spots $n=311$ & $p$-Value \\
\hline History of smoking & & & 0.201 \\
\hline Never & $250(81.7)$ & $236(76.9)$ & \\
\hline Former & $18(5.9)$ & 17 (5.5) & \\
\hline Current & $38(12.4)$ & $54(17.6)$ & \\
\hline History of drinking & & & 0.125 \\
\hline Never & $259(84.6)$ & $239(78.4)$ & \\
\hline Former & $10(3.3)$ & $12(3.9)$ & \\
\hline Current & $37(12.1)$ & $54(17.7)$ & \\
\hline HIV status & & & 0.778 \\
\hline Positive & $1(0.3)$ & $1(0.3)$ & \\
\hline Negative & $278(90.8)$ & $287(92.3)$ & \\
\hline Unknown & $27(8.8)$ & $23(7.4)$ & \\
\hline Diabetes status & & & 0.955 \\
\hline Negative & $280(91.5)$ & $285(91.6)$ & \\
\hline Positive & $25(8.2)$ & $24(7.7)$ & \\
\hline Unknown & $1(0.3)$ & $2(0.6)$ & \\
\hline BCG vaccination history & & & 0.499 \\
\hline Unvaccinated & $46(15)$ & $54(17.4)$ & \\
\hline Vaccinated & $260(85)$ & 257 (82.6) & \\
\hline BMI $\left(\mathrm{kg} / \mathrm{m}^{2}\right)$ & & & 0.708 \\
\hline$<18$ & $31(10.1)$ & 35 (11.3) & \\
\hline $18-24.99$ & $260(85)$ & $257(82.6)$ & \\
\hline$\geq 25$ & $15(4.9)$ & $19(6.1)$ & \\
\hline $\begin{array}{l}\text { Travelling time from home to } \\
\text { medical facility }\end{array}$ & & & 0.076 \\
\hline Greater than one hour & $110(35.9)$ & $90(28.9)$ & \\
\hline Within one hour & $196(64.1)$ & $221(71.1)$ & \\
\hline TST (induration, mm) & & & 0.014 \\
\hline$<5$ & $202(66)$ & $179(57.6)$ & \\
\hline $5-9.9$ & $28(9.2)$ & $21(6.8)$ & \\
\hline $10-14.9$ & $66(21.6)$ & $88(28.3)$ & \\
\hline$\geq 15$ & $10(3.3)$ & $23(7.4)$ & \\
\hline Suspected TB symptoms & & & 0.029 \\
\hline No & $301(98.4)$ & 295 (94.9) & \\
\hline Yes & $5(1.6)$ & $16(5.1)$ & \\
\hline Diagnosis of TB & & & 0.499 \\
\hline Non-TB & $306(100)$ & 309 (99.4) & \\
\hline TB & $0(0)$ & $2(0.6)$ & \\
\hline
\end{tabular}

HIV: Human immunodeficiency virus. BMI: Body mass index. TST: Tuberculin skin test. TB: Tuberculosis.

\subsection{Comparison of the Mtb Genotypes Between Hot and Cold Spots of TB}

A phylogenetic tree of genotypic information from the Mtb isolates for hot and cold spot counties is shown in Figure 3. The major Mtb lineages were Lineage 2 and Lineage 4. Lineage 2.2 represents the Beijing family strain which accounted for $64.6 \%$ in hot spots and $50.7 \%$ in cold spots $(p=0.02)$. The overall proportion of Mtb Lineage 4 was higher in cold spot counties. 
Table 3. Comparison of the household-level variables between cold and hot spot areas.

\begin{tabular}{lccc}
\hline \multicolumn{1}{c}{ Variable } & Cold Spots $n=\mathbf{1 4 4}$ & Hot Spots $\boldsymbol{n}=\mathbf{1 4 7}$ & $\boldsymbol{p}$-Value \\
\hline Number of contacts per household $(n)$ & $2(2,3)$ & $2(1,3)$ & 0.810 \\
TST screening rate $(\%)$ & $100(66.7,100)$ & $100(66.7,100)$ & 0.585 \\
Percentage of children per household $(\%)$ & $0(0,0)$ & $0(0,0)$ & 0.435 \\
Average age (years) & $41.5(34.8,52.8)$ & $44.3(34.4,54.5)$ & 0.271 \\
Average BMI & $20.9(19.8,21.9)$ & $20.7(19.7,21.7)$ & 0.597 \\
Percentage of smokers $(\%)$ & $0(0,30)$ & $0(0,30)$ & 0.152 \\
Per capita size of living area $\left(\mathrm{m}^{2}\right)$ & $30(20,40)$ & $30(20.6,42.7)$ & 0.952 \\
Average diameter of induration $(\mathrm{mm})$ & $2.7(0,6.2)$ & $4.7(0,7.8)$ & 0.005 \\
Positive rate of TST $(\%)$ & $0(0,50)$ & $0.3(0,50)$ & 0.023 \\
\hline
\end{tabular}

Numbers in table are median (inter-quartile range). TST: Tuberculin skin test. IQR: Inter-quartile range. ${ }^{*}$ Children older than five years of age.

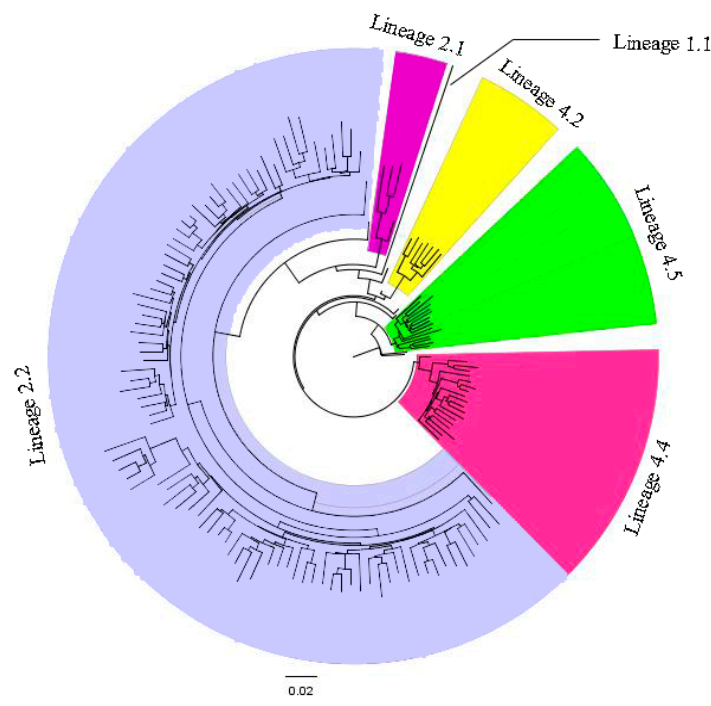

(a)

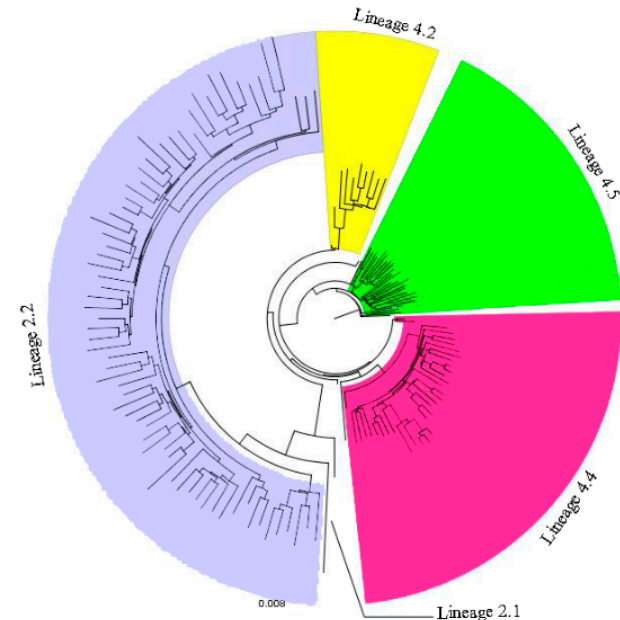

(b)

Figure 3. Phylogenetic tree of Mtb strains found in hot and cold spot counties. (a) Hot spot counties; (b) Cold spot counties.

\subsection{Independent Effects of Locality and Genotypes of the Index Cases on TST Result}

Table 4 summarizes the univariate analysis of factors associated with TST status. Living in a hot spot area, being the spouse of an index case, living in the same room as an index case, having a BCG vaccination, Beijing family genotype, delay in TB diagnosis, and old age were significantly associated with being TST positive.

Table 5 compares models with different independent variable groups included in an incremental fashion. Model 1 contains only the spatial effect. Model 2 adds the Mtb genotype (Beijing vs. non-Beijing families) of the index cases to adjust for the spatial effect. Model 3 added socio-economic factors to test for confounding. Model 4 introduced potential influencing factors such as living in the same room as an index case, BCG vaccination status, and delay in diagnosis of index TB case. Based on the Akaike Information Criterion (AIC) judgment [26], Model 4 was determined as the best fitting model. In all models, both the spatial location $(\mathrm{aOR}=1.61)$ and the genotype of the index case $(\mathrm{aOR}=1.83)$ retained statistical significance throughout. Adding variables such as travelling time from home to a medical facility $\geq 1 \mathrm{~h}(\mathrm{aOR}=4.78)$, living in the same room with an index case $(\mathrm{aOR}=2.29)$, $\mathrm{BCG}$ vaccination status $(\mathrm{aOR}=2.02)$, and delay in diagnosis of the index case $(\mathrm{aOR}=2.56)$ were independently associated with TST status. 
Table 4. Univariate analysis of factors associated with TST status among TB household contacts.

\begin{tabular}{|c|c|c|c|}
\hline Variables & $\operatorname{TST}(-)(n, \%)$ & $\operatorname{TST}(+)(n, \%)$ & $p$-Value \\
\hline Total & 432 & 185 & \\
\hline Locality & & & 0.002 \\
\hline Cold spots & $232(53.7)$ & $74(40)$ & \\
\hline Hot spots & $200(46.3)$ & $111(60)$ & \\
\hline Suspected TB Symptoms & & & 1.000 \\
\hline No & $417(96.5)$ & $179(96.8)$ & \\
\hline Yes & $15(3.5)$ & $6(3.2)$ & \\
\hline TB status & & & 0.510 \\
\hline Non-TB & $431(99.8)$ & 184 (99.5) & \\
\hline $\mathrm{TB}$ & $1(0.2)$ & $1(0.5)$ & \\
\hline Relationship with the index case & & & 0.005 \\
\hline Non-spouse & $323(74.8)$ & $117(63.2)$ & \\
\hline Spouse & $109(25.2)$ & $68(36.8)$ & \\
\hline $\begin{array}{l}\text { Lives in the same room with the } \\
\text { index case }\end{array}$ & & & $<0.001$ \\
\hline No & $250(57.9)$ & $72(38.9)$ & \\
\hline Yes & $182(42.1)$ & $113(61.1)$ & \\
\hline Gender & & & 0.465 \\
\hline Male & $214(49.5)$ & $85(45.9)$ & \\
\hline Female & $218(50.5)$ & $100(54.1)$ & \\
\hline Age group (years) & & & 0.145 \\
\hline$<40$ & $197(45.6)$ & $93(50.3)$ & \\
\hline$\geq 60$ & $74(17.1)$ & $38(20.5)$ & \\
\hline $40-59$ & $161(37.3)$ & $54(29.2)$ & \\
\hline Ethnicity & & & 0.452 \\
\hline Han & $234(54.2)$ & $95(51.4)$ & \\
\hline Others & $20(4.6)$ & $13(7)$ & \\
\hline Zhuang & $178(41.2)$ & 77 (41.6) & \\
\hline Education & & & 0.592 \\
\hline None & $36(8.3)$ & $10(5.4)$ & \\
\hline Primary school & 167 (38.7) & $75(40.5)$ & \\
\hline Middle school & $151(35)$ & $62(33.5)$ & \\
\hline High school & $57(13.2)$ & $25(13.5)$ & \\
\hline University & $21(4.9)$ & $13(7)$ & \\
\hline Occupation & & & 0.617 \\
\hline Civil servant & $8(1.9)$ & $3(1.6)$ & \\
\hline Farmer & $268(62)$ & $107(57.8)$ & \\
\hline Migrant worker & $34(7.9)$ & $19(10.3)$ & \\
\hline Others & $54(12.5)$ & $20(10.8)$ & \\
\hline Student & $68(15.7)$ & $36(19.5)$ & \\
\hline Marital status & & & 0.599 \\
\hline Married & $288(66.7)$ & $118(63.8)$ & \\
\hline Single & $105(24.3)$ & $52(28.1)$ & \\
\hline Others & $39(9)$ & $15(8.1)$ & \\
\hline Income per month (Renminbi) & & & 0.507 \\
\hline$\leq 3000$ & $336(77.8)$ & $151(81.6)$ & \\
\hline $3001-4000$ & $62(14.4)$ & $26(14.1)$ & \\
\hline $4001-5000$ & $28(6.5)$ & $7(3.8)$ & \\
\hline$>5000$ & $6(1.4)$ & $1(0.5)$ & \\
\hline
\end{tabular}


Table 4. Cont.

\begin{tabular}{|c|c|c|c|}
\hline Variables & $\operatorname{TST}(-)(n, \%)$ & $\operatorname{TST}(+)(n, \%)$ & $p$-Value \\
\hline TB patients in family & & & 0.808 \\
\hline No & $300(69.4)$ & $131(70.8)$ & \\
\hline Yes & $132(30.6)$ & $54(29.2)$ & \\
\hline History of smoking & & & 0.522 \\
\hline Never & $336(78.3)$ & $150(81.5)$ & \\
\hline Former & $24(5.6)$ & $11(6)$ & \\
\hline Current & $69(16.1)$ & $23(12.5)$ & \\
\hline History of drinking alcohol & & & 0.808 \\
\hline Never & 349 (81.7) & $149(81)$ & \\
\hline Former & $14(3.3)$ & $8(4.3)$ & \\
\hline Current & $64(15)$ & $27(14.7)$ & \\
\hline HIV status & & & 0.188 \\
\hline Positive & $1(0.2)$ & $1(0.5)$ & \\
\hline Negative & $391(90.5)$ & $174(94.1)$ & \\
\hline Unknown & $40(9.3)$ & $10(5.4)$ & \\
\hline Diabetes status & & & 0.944 \\
\hline Negative & $395(91.4)$ & $170(91.9)$ & \\
\hline Positive & $35(8.1)$ & $14(7.6)$ & \\
\hline Unknown & $2(0.5)$ & $1(0.5)$ & \\
\hline BCG vaccination history & & & 0.024 \\
\hline Unvaccinated & $80(18.5)$ & $20(10.8)$ & \\
\hline Vaccinated & $352(81.5)$ & $165(89.2)$ & \\
\hline BMI $\left(\mathrm{kg} / \mathrm{m}^{2}\right)$ & & & 0.591 \\
\hline$<18$ & $48(11.1)$ & $18(9.7)$ & \\
\hline $18-24.99$ & $358(82.9)$ & $159(85.9)$ & \\
\hline$\geq 25$ & $26(6)$ & $8(4.3)$ & \\
\hline Outside travel greater than 3 month & & & 0.599 \\
\hline No & $364(85)$ & $151(83)$ & \\
\hline Yes & $64(15)$ & $31(17)$ & \\
\hline $\begin{array}{l}\text { Travelling time from home to } \\
\text { medical facility }\end{array}$ & & & $<0.001$ \\
\hline Greater than one hour & $332(76.9)$ & $85(45.9)$ & \\
\hline Within one hour & $100(23.1)$ & $100(54.1)$ & \\
\hline Mtb genotype of the index case & & & $<0.001$ \\
\hline Non-Beijing & $195(45.1)$ & $53(28.6)$ & \\
\hline Beijing & $237(54.9)$ & $132(71.4)$ & \\
\hline Gender of the index case & & & 0.302 \\
\hline Male & $325(75.2)$ & $147(79.5)$ & \\
\hline Female & $107(24.8)$ & $38(20.5)$ & \\
\hline The age group of the index case & & & 0.035 \\
\hline$<40$ & $136(31.5)$ & $41(22.2)$ & \\
\hline $40-59$ & $140(32.4)$ & $76(41.1)$ & \\
\hline$\geq 60$ & $156(36.1)$ & $68(36.8)$ & \\
\hline Delay for index TB diagnosis & & & 0.002 \\
\hline Yes & $369(85.4)$ & $175(94.6)$ & \\
\hline No & $63(14.6)$ & $10(5.4)$ & \\
\hline
\end{tabular}

TB: Tuberculosis. Mtb: Mycobacterium tuberculosis. HIV: Human immunodeficiency virus. BMI: Body mass index. TST: Tuberculin skin test. 
Table 5. Results of multivariate analysis of factors associated with tuberculin skin test result (aOR 95\% CI).

\begin{tabular}{|c|c|c|c|c|}
\hline Variable & Model 1 & Model 2 & Model 3 & Model 4 \\
\hline Spatial area & $1.75(1.22,2.50)$ & $1.57(1.09,2.25)$ & $2.70(1.12,6.51)$ & $1.61(1.05,2.45)$ \\
\hline Index genotype & & $1.90(1.29,2.79)$ & $1.93(1.25,2.97)$ & $1.83(1.19,2.81)$ \\
\hline $\begin{array}{l}\text { SES (Ethnicity, Income, Education, } \\
\text { Occupation, Marital status, Travelling } \\
\text { time from home to the medical facility) }\end{array}$ & & & $\begin{array}{l}\text { Long travelling: } \\
4.71(2.84,7.81)\end{array}$ & $\begin{array}{l}\text { Long travelling: } \\
4.78(2.96,7.72)\end{array}$ \\
\hline $\begin{array}{l}\text { Others (Lives in the same room as the } \\
\text { index case, history of BCG vaccination, } \\
\text { delay in diagnosis) }\end{array}$ & & & & $\begin{array}{l}\text { Same room: } 2.29(1.50,3.49) \\
\text { BCG vaccinated: } 2.02(1.13, \\
\text { 3.62) Delay: } 2.56(1.13,5.80)\end{array}$ \\
\hline AIC & 749.75 & 740.52 & 679.23 & 659.66 \\
\hline
\end{tabular}

AIC: Akaike Information Criterion.

\section{Discussion}

$\mathrm{TB}$ cases from hot spot county areas were more likely to belong to a minority ethnic group, have a lower socioeconomic status, be in poor physical condition, and have a delay in diagnosis compared to those from cold spot areas. The proportion of cases having the Beijing family genotype $(64.6 \%)$ in hot spot areas was significantly higher than that in cold spot areas (50.7\%). The TST positive rate among household contacts in the hot spot areas was 35.7\%, significantly higher than that in cold spot areas (24.2\%); and with multivariate analysis, it remained significantly associated with the location. Genotype (Beijing vs. non-Beijing) was also significantly associated with TST status even after adjusting for travelling time from home to medical facility, BCG vaccination status and delay in diagnosis. Income and education had no effect on TST results. Ethnicity, however, lost its significance due to the confounding effect of the travelling time.

The association between TB and socio-economic status has been well documented [27-32]. The hot spot areas were predominated by those individuals with low socioeconomic status, which we first believed to be the explanation for Mtb transmission. We did not find support for the association because income, education and occupation were not associated with the household transmission, and ethnicity lost its significant effect after adjustment for travelling time and other potential influencing factors. Thus, travelling time might be the final common path of causation between socio-economic status and TB household transmission $(\mathrm{aOR}=4.78)$. The long travelling time from home to medical facilities implicates poor access to health services. In particular, family members with active tuberculosis may become super-spreaders, spreading mycobacterium tuberculosis in their household, due to their failure to receive timely diagnosis and standard treatment. Thus, this factor increases the local TB burden. Our finding at the county level supported this hypothesis. Cold spot county areas had three times as many medical facilities as the hot spot county areas. This predictor is consistent with a household tracing study conducted in Tunisia [33].

In addition to a long travelling time, other host factors were also associated with Mtb intra-household transmission in this study. Delay in TB diagnosis of the index TB case provided a long-term exposure of Mtb to the household contacts $(\mathrm{aOR}=2.56)$. Studies conducted in Sudan and western China had similar results [34,35]. Most of the active TB patients in the hot spot areas still shared a bedroom with household contacts. This behavior increased the chance of TB infection $(\mathrm{aOR}=2.29)$ due to the limited living areas of households and low awareness of TB prevention by the inhabitants. This predictive factor has also been reported by Jones-Lopez in a study from Brazil [36].

The ability of specific Mtb pathogens to disseminate plays a critical role in the TB epidemic [37]. Our analysis confirmed that the Beijing family genotype strains in the index TB cases were more prevalent in areas where spatial clustering was high. Beyond that, this strain increased the risk of household TB transmission compared to non-Beijing genotypes after adjusting for other risk factors $(\mathrm{aOR}=1.83)$. The Beijing genotype family is widespread in Asian countries and also in the United 
States [38,39]. These strains are considered to be related to immune escape from BCG protection, increasing virulence, drug resistance, and transmissibility [40]. Beijing genotype strains have been shown to be a TB complex associated with drug-resistance, which is more common in hot spot areas [41]. Compared with northern China, the distribution of Beijing strains in our two research sites is relatively low [42-44]. The level of importance of the TB complex on transmission, therefore, varies across different cofactors such as the environment and population mobility. Guangxi is adjacent to southeast Asian countries, and frequent economic and cultural communication with these countries may also lead to the exchanges of different Mtb lineages, and thus, the genomic polymorphism becomes greater.

The detection rate of LTBI in the hot spot county areas was 35.7\%, higher than that in cold spot county areas $(24.2 \%)$ and other regions with low TB incidence $[45,46]$. After controlling for other factors, the geographic location proved to be an independent factor for household Mtb transmission $(\mathrm{aOR}=1.61)$. This significant effect could not be explained by other variables that were included in the model. In the hot spot county areas, these TB transmission promotors from outside of the household may be more common, but this supposition is unclear in the current study. However, more unknown mechanisms outside the household would need further studies.

A TST (induration $\geq 10 \mathrm{~mm}$ ) was used to investigate LTBI among household contacts in the current study. The TST result may be difficult to distinguish between an Mtb infection, vaccination of BCG, and non-tuberculosis mycobacteria infection, and has low specificity. However, from a meta-analysis of studies in mainland China, the non-tuberculosis mycobacteria infection rate was about $6.3 \%$ (range: $5.4-7.4 \%$ ) in tuberculosis suspected population. In our study, the non-tuberculosis mycobacteria detection rate was only $2.7 \%(8 / 291)$. Thus, it is unlikely that the exposure of non-tuberculosis mycobacteria affected TST specificity. Studies from China, Germany, and Australia identified that the main reason affecting TST judgment of LTBI was BCG vaccination [47-49]. The results of this study also support this viewpoint $(\mathrm{aOR}=2.02)$ and are similar to studies from Singapore and Gambia $[50,51]$. Interferon-gamma release assay (IGRAs) is an alternative method for LTBI diagnosis. However, due to the high cost of testing, it is still not widely available in high-epidemic, developing countries. Thus, WHO has declared that in areas of high TB prevalence, IGRAs should not replace the TST for identification of individuals with LTBI [22,52].

In this study, we could not obtain Mtb isolates from household contacts and have not determined the transmission dynamics outside the household. The relationships involving Mtb transmission outside the household are known to be associated with environmental factors and should be taken into account in future studies.

\section{Conclusions}

The findings of this study confirmed the strong transmissibility of the Beijing genotype family strains and this genotype's important role in household transmission. We found that an extended traveling time from home to the medical facility was an important socioeconomic factor for Mtb transmission in the family which is consistent with a study conducted in the Yunnan Province of China in 2005 [35]. Over the past decade, in most districts of Guangxi, the diagnosis and treatment of TB has shifted from county-level CDC clinics to county-level designated hospitals having advanced diagnostic equipment, but poor access to medical facilities remains a significant risk factor for Mtb household transmission. Thus, it is still necessary to improve the medical facility infrastructure and management, especially in areas with a high TB prevalence.

Author Contributions: V.C., Z.C. and D.L. contributed to the study design, preparation of materials, data collection, data analysis, and manuscript writing. E.A.G. contributed to the study design and manuscript writing. A.C. and P.P. contributed to the manuscript writing. M.L. and J.O. contributed to the study design and data collection. J.Z. contributed to the data collection.

Funding: This work was supported by the National Natural Science Foundation of China (81760603), Guangxi National Natural Science Foundation (2018GXNSFAA281018). The study was part of the Ph.D. thesis of the first author to fulfill the requirement for the tuberculosis research training program at the Epidemiology Unit, 
Prince of Songkla University, under the support of the Fogarty International Center, National Institutes of Health (D43TW009522).

Acknowledgments: We thank Edward McNeil and Wit Wichaidit from Prince of Songkla University, Songkhla, Thailand for their useful comments on this manuscript. We would also like to thank all the health workers for their assistance in performing the survey.

Conflicts of Interest: The authors declare no conflict of interest.

\section{References}

1. Hajat, C.; Stein, E. The global burden of multiple chronic conditions: A narrative review. Prev. Med Rep. 2018, 12, 284-293. [CrossRef]

2. Global Tuberculosis Report. Available online: https://www.who.int/tb/publications/global_report/en/ (accessed on 10 March 2019).

3. Liang, D.; Huang, M.; Lin, M.; Lin, D.; Lan, R. Analysis of tuberculosis prevalence in Guangxi from 2011 to 2015. J. Appl. Prev. Med. 2017, 23, 133-138.

4. $\quad$ Lin, M.; Cui, Z.Z.; Lin, D.W.; Liang, D.B.; Huang, M.Y.; Su, H.B.; Tang, X.Y. Visual-spatial and temporal characteristics related to infectious Tuberculosis epidemics in Guangxi Zhuang Autonomous Region, 2012-2015. Chin. J. Epidemiol. 2017, 38, 1206-1211.

5. Cui, Z.; Lin, D.; Chongsuvivatwong, V.; Zhao, J.; Lin, M.; Ou, J.; Zhao, J. Spatiotemporal patterns and ecological factors of tuberculosis notification: A spatial panel data analysis in Guangxi, China. PLoS ONE 2019, 14, e0212051. [CrossRef]

6. Yang, X.; Zhou, H.; Pan, X. Exploration on the risk factors of pulmonary tuberculosis incidence in Wenchuan earthquake-stricken area. J. Evid. Based Med. 2017, 10, 281-286. [CrossRef]

7. Chen, H.; He, L.; Cai, C.; Liu, J.; Jia, J.; Ma, L.; Huang, H.; Wang, L.; Ni, X.; Gao, J.; et al. Characteristics of distribution of Mycobacterium tuberculosis lineages in China. Sci. China Life Sci. 2018, 61, 651-659. [CrossRef]

8. Merker, M.; Blin, C.; Mona, S.; Duforet-Frebourg, N.; Lecher, S.; Willery, E.; Blum, M.G.B.; Ruch-Gerdes, S.; Mokrousov, I.; Aleksic, E.; et al. Evolutionary history and global spread of the Mycobacterium tuberculosis Beijing lineage. Nat. Genet. 2015, 47, 242-249. [CrossRef]

9. Orgeur, M.; Brosch, R. Evolution of virulence in the Mycobacterium tuberculosis complex. Curr. Opin. Microbiol. 2018, 41, 68-75. [CrossRef]

10. Coll, F.; McNerney, R.; Guerra-Assuncao, J.A.; Glynn, J.R.; Perdigao, J.; Viveiros, M.; Portugal, I.; Pain, A.; Martin, N.; Clark, T.G. A robust SNP barcode for typing Mycobacterium tuberculosis complex strains. Nat. Commun. 2014, 5, 4812. [CrossRef] [PubMed]

11. Wada, T.; Hijikata, M.; Maeda, S.; Hang, N.T.L.; Thuong, P.H.; Hoang, N.P.; Hung, N.V.; Keicho, N. Complete Genome Sequences of Three Representative Mycobacterium tuberculosis Beijing Family Strains Belonging to Distinct Genotype Clusters in Hanoi, Vietnam, during 2007 to 2009. Genome Announc. 2017, 5, 2. [CrossRef] [PubMed]

12. Liu, Q.; Luo, T.; Dong, X.; Sun, G.; Liu, Z.; Gan, M.; Wu, J.; Shen, X.; Gao, Q. Genetic features of Mycobacterium tuberculosis modern Beijing sublineage. Emerg Microbes Infect. 2016, 5, e14. [CrossRef] [PubMed]

13. Feltcher, M.E.; Gibbons, H.S.; Ligon, L.S.; Braunstein, M. Protein Export by the Mycobacterial SecA2 System Is Determined by the Preprotein Mature Domain. J. Bacteriol. 2013, 195, 672-681. [CrossRef] [PubMed]

14. Jones, R.C.; Harris, L.G.; Morgan, S.; Ruddy, M.C.; Perry, M.; Williams, R.; Humphrey, T.; Temple, M.; Davies, A.P. Phylogenetic analysis of Mycobacterium tuberculosis strains in Wales using core genome MLST to analyse whole genome sequencing data. J. Clin. Microbiol. 2019. [CrossRef] [PubMed]

15. Shimeles, E.; Enquselassie, F.; Aseffa, A.; Tilahun, M.; Mekonen, A.; Wondimagegn, G.; Hailu, T. Risk factors for tuberculosis: A case-control study in Addis Ababa, Ethiopia. PLoS ONE 2019, 14, e0214235. [CrossRef] [PubMed]

16. Morrison, J.; Pai, M.; Hopewell, P.C. Tuberculosis and latent tuberculosis infection in close contacts of people with pulmonary tuberculosis in low-income and middle-income countries: A systematic review and meta-analysis. Lancet Infect. Dis. 2008, 8, 359-368. [CrossRef] 
17. Pan, D.X.; Lin, M.; Lan, R.S.; Graviss, E.A.; Lin, D.W.; Liang, D.B.; Long, X.; Qin, H.F.; Huang, L.W.; Huang, M.Y.; et al. Tuberculosis Transmission in Households and Classrooms of Adolescent Cases Compared to the Community in China. Int. J. Environ. Res. Public Health 2018, 15, 2803. [CrossRef] [PubMed]

18. Htet, K.K.K.; Liabsuetrakul, T.; Thein, S.; McNeil, E.B.; Chongsuvivatwong, V. Improving detection of tuberculosis among household contacts of index tuberculosis patients by an integrated approach in Myanmar: A cross-sectional study. BMC Infect. Dis. 2018, 18, 660. [CrossRef]

19. Fleiss, J.L.; Bruce, L.; Myunghee, C.P. Statistical Methods for Rates and Proportions, 3rd ed.; Wiley series in probability and statistics; Wiley: Hoboken, NJ, USA, 2003; p. 760.

20. Luo, D.; Lan, L.; Zhao, J.; Zhang, Y.; Lan, R. Variable number tandem repeats diversity of Mycobacterium tuberculosis isolates. Chin. J. Infect. Dis. 2016, 34, 490-492.

21. Zou, L.; Susko, E.; Field, C.; Roger, A.J. Fitting nonstationary general-time-reversible models to obtain edge-lengths and frequencies for the barry-hartigan model. Syst. Biol. 2012, 61, 927-940. [CrossRef]

22. Latent Tuberculosis Infection: Updated and consolidated guidelines for programmatic management. Available online: https://apps.who.int/iris/bitstream/handle/10665/260233/9789241550239-eng.pdf?sequence= 1 (accessed on 11 March 2019).

23. Song, Q.; Guo, H.; Zhong, H.; Liu, Z.; Chen, X.; Wang, C.; Touzjian, N.; Lv, Y.; Lu, X.; Wang, Q. Evaluation of a new interferon-gamma release assay and comparison to tuberculin skin test during a tuberculosis outbreak. Int. J. Infect. Dis. 2012, 16, e522-e526. [CrossRef]

24. Diagnosis for Pulmonary Tuberculosis (WS 288-2017). Available online: http://www.nhc.gov.cn/ewebeditor/ uploadfile/2017/11/20171128164254246.pdf (accessed on 11 March 2019).

25. Hosmer, D.W.; Lemeshow, S.; Sturdivant, R.X. Applied Logistic Regression, 3rd ed.; Wiley: Hoboken, NJ, USA, 2013; p. 500.

26. Donohue, M.C.; Overholser, R.; Xu, R.; Vaida, F. Conditional Akaike information under generalized linear and proportional hazards mixed models. Biometrika 2011, 98, 685-700. [CrossRef] [PubMed]

27. Olson, N.A.; Davidow, A.L.; Winston, C.A.; Chen, M.P.; Gazmararian, J.A.; Katz, D.J. A national study of socioeconomic status and tuberculosis rates by country of birth, United States, 1996-2005. BMC Public Health 2012, 12, 365. [CrossRef] [PubMed]

28. Taylan, M.; Demir, M.; Yilmaz, S.; Kaya, H.; Sen, H.S.; Oruc, M.; Icer, M.; Gunduz, E.; Sezgi, C. Effect of human development index parameters on tuberculosis incidence in Turkish provinces. J. Infect. Dev. Ctries. 2016, 10, 1183-1190. [CrossRef]

29. San Pedro, A.; Oliveira, R.M. Tuberculosis and socioeconomic indicators: Systematic review of the literature. Rev. Panam. Salud Publica 2013, 33, 294-301. [CrossRef]

30. Rengganis Wardani, D.W.S.; Wahono, E.P. Prediction Model of Tuberculosis Transmission Based on Its Risk Factors and Socioeconomic Position in Indonesia. Indian J. Community Med. 2018, 43, 204-208.

31. McKeown, T.; Record, R.G. Reasons for the decline of mortality in England and Wales during the nineteenth century. PLOS ONE 1962, 16, 94-122.

32. Tripp, L.; Sawchuk, L.A. Insights into secular trends of respiratory tuberculosis: The 20th century Maltese experience. PLoS ONE 2017, 12, e0183296. [CrossRef] [PubMed]

33. Berraies, A.; Hamdi, B.; Ammar, J.; Snen, H.; Bouhaouel, W.; Hamzaoui, A. Results of tuberculosis screening in children with household contact. Rev. Pneumol. Clin. 2016, 72, 184-189. [CrossRef]

34. Mohamed, E.Y.; Abdalla, S.M.; Khamis, A.A.; Abdelbadea, A.; Abdelgadir, M.A. Factors associated with patient delay in accessin pulmonary tuberculosis care, Gezira State, Sudan. East. Mediterr. Health J. 2013, 19, 114-118. [CrossRef]

35. Xu, L.; Chongsuvivatwong, V.; Lu, L.; Geater, A.; Ren, L.J. Dose-response relationship between treatment delay of smear-positive tuberculosis patients and intra-household transmission: A cross-sectional study. Trans. R. Soc. Trop. Med. Hyg. 2008, 102, 797-804.

36. Jones-Lopez, E.C.; Acuna-Villaorduna, C.; Fregona, G.; Marques-Rodrigues, P.; White, L.F.; Hadad, D.J.; Dutra-Molina, L.P.; Vinhas, S.; McIntosh, A.I.; Gaeddert, M.; et al. Incident Mycobacterium tuberculosis infection in household contacts of infectious tuberculosis patients in Brazil. BMC Infect. Dis. 2017, 17, 576. [CrossRef]

37. Elegail, A.; Ibrahim Mohamed, N.Y.; Mohamed Nour, E.O.; Hoffner, S.; Haile, M. Molecular characterization of Mycobacterium tuberculosis isolates from pulmonary tuberculosis patients in Khartoum, Sudan. Int. J. Mycobacteriol. 2018, 7, 236-241. 
38. Shitikov, E.; Kolchenko, S.; Mokrousov, I.; Bespyatykh, J.; Ischenko, D.; Ilina, E.; Govorun, V. Evolutionary pathway analysis and unified classification of East Asian lineage of Mycobacterium tuberculosis. Sci. Rep. 2017, 7, 9227. [CrossRef] [PubMed]

39. Driscoll, J.R. Spoligotyping for molecular epidemiology of the Mycobacterium tuberculosis complex. Methods Mol. Biol. 2009, 551, 117-128. [PubMed]

40. Liu, Y.; Zhang, X.; Zhang, Y.; Sun, Y.; Yao, C.; Wang, W.; Li, C. Characterization of Mycobacterium tuberculosis strains in Beijing, China: Drug susceptibility phenotypes and Beijing genotype family transmission. BMC Infect. Dis. 2018, 18, 658. [CrossRef] [PubMed]

41. Luo, D.; Zhao, J.; Lin, M.; Liu, F.; Huang, S.; Zhang, Y.; Huang, M.; Li, J.; Zhou, Y.; Lan, R.; et al. Drug Resistance in Newly Presenting and Previously Treated Tuberculosis Patients in Guangxi Province, People's Republic of China. Asia Pac. J. Public Health 2017, 29, 296-303. [CrossRef]

42. Chen, J.; Tsolaki, A.G.; Shen, X.; Jiang, X.; Mei, J.; Gao, Q. Deletion-targeted multiplex PCR (DTM-PCR) for identification of Beijing/W genotypes of Mycobacterium tuberculosis. Tuberculosis 2007, 87, 446-449. [CrossRef]

43. Zhao, F.; Cheng, S.; He, G.; Huang, F.; Zhang, H.; Xu, B.; Murimwa, T.C.; Cheng, J.; Hu, D.; Wang, L. Space-time clustering characteristics of tuberculosis in China, 2005-2011. PLoS ONE 2013, 8, e83605. [CrossRef]

44. Sun, W.; Gong, J.; Zhou, J.; Zhao, Y.; Tan, J.; Ibrahim, A.; Zhou, Y. A Spatial, Social and Environmental Study of Tuberculosis in China Using Statistical and GIS Technology. Int. J. Environ. Res. Public Health 2015, 12, 1425-1448. [CrossRef]

45. Liu, Y.; Huang, S.; Jiang, H.; Xiong, J.; Wang, Y.; Ou, M.; Cai, J.; Yang, C.; Wang, Z.; Ge, S.; et al. The prevalence of latent tuberculosis infection in rural Jiangsu, China. Public Health 2017, 146, 39-45. [CrossRef]

46. Gao, L.; Lu, W.; Bai, L.; Wang, X.; Xu, J.; Catanzaro, A.; Cardenas, V.; Li, X.; Yang, Y.; Du, J.; et al. Latent tuberculosis infection in rural China: baseline results of a population-based, multicentre, prospective cohort study. Lancet Infect. Dis. 2015, 15, 310-319. [CrossRef]

47. He, G.X.; van den Hof, S.; van der Werf, M.J.; Wang, G.J.; Ma, S.W.; Zhao, D.Y.; Hu, Y.L.; Yu, S.C.; Borgdorff, M.W. Infection control and the burden of tuberculosis infection and disease in health care workers in china: A cross-sectional study. BMC Infect. Dis. 2010, 10, 313. [CrossRef]

48. Schablon, A.; Harling, M.; Diel, R.; Nienhaus, A. Risk of latent TB infection in individuals employed in the healthcare sector in Germany: A multicentre prevalence study. BMC Infect. Dis. 2010, 10, 107. [CrossRef]

49. Vinton, P.; Mihrshahi, S.; Johnson, P.; Jenkin, G.A.; Jolley, D.; Biggs, B.A. Comparison of QuantiFERON-TB Gold In-Tube Test and Tuberculin Skin Test for Identification of Latent Mycobacterium tuberculosis Infection in Healthcare Staff and Association Between Positive Test Results and Known Risk Factors for Infection. Infect. Control Hosp. Epidemiol. 2009, 30, 215-221. [CrossRef]

50. Lee, H.W.; Lee, Y.J.; Kim, S.J.; Park, J.S.; Cho, Y.J.; Yoon, H.I.; Lee, C.T.; Lee, J.H. Comparing tuberculin skin test and interferon gamma release assay (T-SPOT.TB) to diagnose latent tuberculosis infection in household contacts. Korean J. Intern. Med. 2017, 32, 486-496. [CrossRef]

51. Adetifa, I.M.; Ota, M.O.; Jeffries, D.J.; Hammond, A.; Lugos, M.D.; Donkor, S.; Patrick, O.; Adegbola, R.A.; Hill, P.C. Commercial interferon gamma release assays compared to the tuberculin skin test for diagnosis of latent Mycobacterium tuberculosis infection in childhood contacts in the Gambia. Pediatr. Infect. Dis. J. 2010, 29, 439-443. [CrossRef]

52. Auguste, P.; Tsertsvadze, A.; Pink, J.; Court, R.; McCarthy, N.; Sutcliffe, P.; Clarke, A. Comparing interferon-gamma release assays with tuberculin skin test for identifying latent tuberculosis infection that progresses to active tuberculosis: Systematic review and meta-analysis. BMC Infect. Dis. 2017, 17, 200. [CrossRef]

(C) 2019 by the authors. Licensee MDPI, Basel, Switzerland. This article is an open access article distributed under the terms and conditions of the Creative Commons Attribution (CC BY) license (http://creativecommons.org/licenses/by/4.0/). 